\title{
The Integration of Process Heat Applications to High Temperature Gas Reactors
}

\section{IMECE 2011}

\author{
Michael G. McKellar
}

U.S. Department of Energy

National Laboratory

operated by

Battelle Energy Alliance

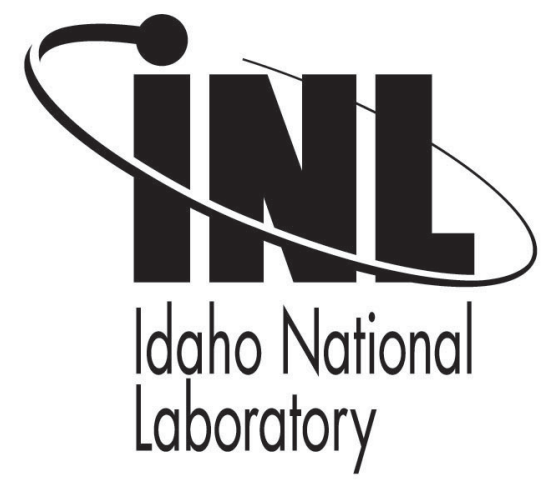

This is a preprint of a paper intended for publication in a journal or proceedings. Since changes may be made before publication, this preprint should not be cited or reproduced without permission of the author. This document was prepared as an account of work sponsored by an agency of the United States Government. Neither the United States Government nor any agency thereof, or any of their employees, makes any warranty, expressed or implied, or assumes any legal liability or responsibility for any third party's use, or the results of such use, of any information, apparatus, product or process disclosed in this report, or represents that its use by such third party would not infringe privately owned rights. The views expressed in this paper are not necessarily those of the United States Government or the sponsoring agency. 


\title{
THE INTEGRATION OF PROCESS HEAT APPLICATIONS TO HIGH TEMPERATURE GAS REACTORS
}

\author{
Michael G. McKellar \\ Idaho National Laboratory \\ Idaho Falls, ID 83415, USA
}

\begin{abstract}
A high temperature gas reactor, HTGR, can produce industrial process steam, high-temperature heat-transfer gases, and/or electricity. In conventional industrial processes, these products are generated by the combustion of fossil fuels such as coal and natural gas, resulting in significant emissions of greenhouse gases such as carbon dioxide. Heat or electricity produced in an HTGR could be used to supply process heat or electricity to conventional processes without generating any greenhouse gases. Process heat from a reactor needs to be transported by a gas to the industrial process. Two such gases were considered in this study: helium and steam. For this analysis, it was assumed that steam was delivered at $17 \mathrm{MPa}$ and $540^{\circ} \mathrm{C}$ and helium was delivered at $7 \mathrm{MPa}$ and at a variety of temperatures. The temperature of the gas returning from the industrial process and going to the HTGR must be within certain temperature ranges to maintain the correct reactor inlet temperature for a particular reactor outlet temperature. The returning gas may be below the reactor inlet temperature, ROT, but not above. The optimal return temperature produces the maximum process heat gas flow rate. For steam, the delivered pressure sets an optimal reactor outlet temperature based on the condensation temperature of the steam. ROTs greater than $769.7^{\circ} \mathrm{C}$ produce no additional advantage for the production of steam.
\end{abstract}

\section{INTRODUCTION}

The paper comes from study that was prepared as part of a project for the Next Generation Nuclear Plant (NGNP) Project to evaluate integration of high-temperature gas-cooled reactor (HTGR) technology with conventional chemical processes. The NGNP Project is being conducted under U.S. Department of Energy (DOE) direction to meet a national strategic need identified in the National Energy Policy to promote reliance on safe, clean, economic nuclear energy and to establish a greenhouse-gas-free technology for the production of hydrogen. The NGNP represents an integration of high-temperature reactor technology with advanced hydrogen, electricity, and process heat production capabilities, thereby meeting the mission need identified by DOE. The strategic goal of the NGNP Project is to broaden the environmental and economic benefits of nuclear energy in the U.S. economy by demonstrating its applicability to market sectors not being served by light water reactors.

An HTGR produces steam, high-temperature helium, or electricity. In conventional processes, these products are generated by the combustion of fossil fuels such as coal and natural gas, resulting in significant emissions of greenhouse gases such as carbon dioxide. Heat or electricity produced in an HTGR could be used to supply process heat or electricity to conventional processes without generating any greenhouse gases. The use of an HTGR to supply process heat or electricity to conventional processes is referred to as a nuclearintegrated process. This paper describes how the reactor outlet temperature affects heat integration.

The purpose of this study is to present the process modeling results of the effects of the reactor outlet temperature on producing heat using a high-temperature gas reactor. These results are used in other process models developed under the NGNP program where HTGR-integrated heat may be integrated with industrial processes.

The Advanced Process and Decision Systems Department at Idaho National Laboratory (INL) has spent several years developing detailed process simulations of chemical and thermodynamic processes. These simulations have been developed using HYSYS Process and ASPEN PLUS - stateof-the-art, steady-state, thermodynamic, and chemical process simulators developed by Hyprotech and ASPEN. This study makes extensive use of these models and the modeling capability at INL to evaluate the integration of HTGR technology with potential industrial processes. 


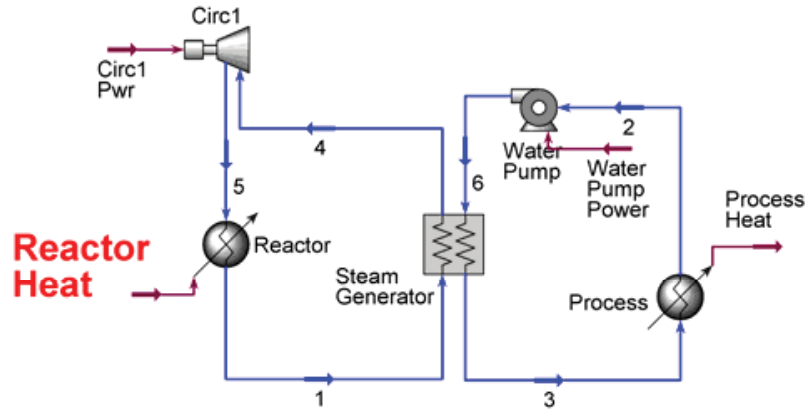

Figure 1. Steam and helium process heat HYSYS models.

\section{PROCESS MODELS}

Two relatively simple process models were developed to analyze this problem: one for steam and one for helium process heat. Figure 1 shows the process models. The following assumptions are used for the analysis

- Heat exchangers have minimum approach temperatures of $25 \mathrm{C}$.

- The circulators have adiabatic efficiencies of $80 \%$

- The pumps have adiabatic efficiencies of $75 \%$.

- $2 \%$ nominal pressure drops occur within the heat exchangers and heaters

- A 600 MWth reactor supplies the heat in the primary loop.

For both models two loops are used, a primary reactor loop and a secondary process heat loop. For the steam case, the steam is usually condensed and a pump is used to circulate the water into the steam generator. In some cases however, the steam never condenses and the pump is replace by a compressor. For the helium case, a circulator is always used on both the primary and secondary loops. It is assumed for the steam case that steam is produced at $540 \mathrm{C}$ and $17 \mathrm{MPa}$. The helium is produced at temperature $25 \mathrm{C}$ below the reactor outlet temperature (due to the minium approach within the intermediate heat exchanger, IHX) and $7 \mathrm{MPa}$.

To evaluate the effect of the reactor outlet temperature (ROT) on process heat generation, the reactor inlet temperature (RIT) must be known. Given the reactors inlet and outlet core temperatures, the mass flow of helium through the core can be calculated. As will be shown later in this paper, the reactor inlet temperature determines the maximum flow rate of the process heat loop. For this study a number of papers and books [1-10] were referenced to determine the reactor inlet temperature as a function of the reactor outlet temperature. The data were plotted and a least squares function developed.

$$
\text { RIT }=0.821 * \text { ROT }-243
$$

Figure 2 is a plot of the reactor outlet temperature, the reactor inlet temperature calculated from equation 1 , and the flow rate of helium through the reactor calculated from the process model. As the reactor outlet temperature increases, the reactor inlet temperature increases but not as rapidly. For every degree increase in the outlet temperature, the inlet temperature increases only 0.82 degrees. The temperature difference between the outlet and inlet temperature increases as the outlet temperature increases which causes the helium mass flow rate to decrease.

\section{RESULTS}

To analyze the steam case, a parametric study was made in which both the ROT and the process heat return temperature were varied. The results of this study are plotted in Figure 3.

The maximum process return temperature is determined by one of two conditions. For ROT of $770^{\circ} \mathrm{C}$ and below, the maximum process return temperature is set by the minimum approach temperature of the steam generator. Above a ROT of $770^{\circ} \mathrm{C}$, the process return temperature is set at the saturated liquid condition to ensure pumping. At the ROT of $770^{\circ} \mathrm{C}$,

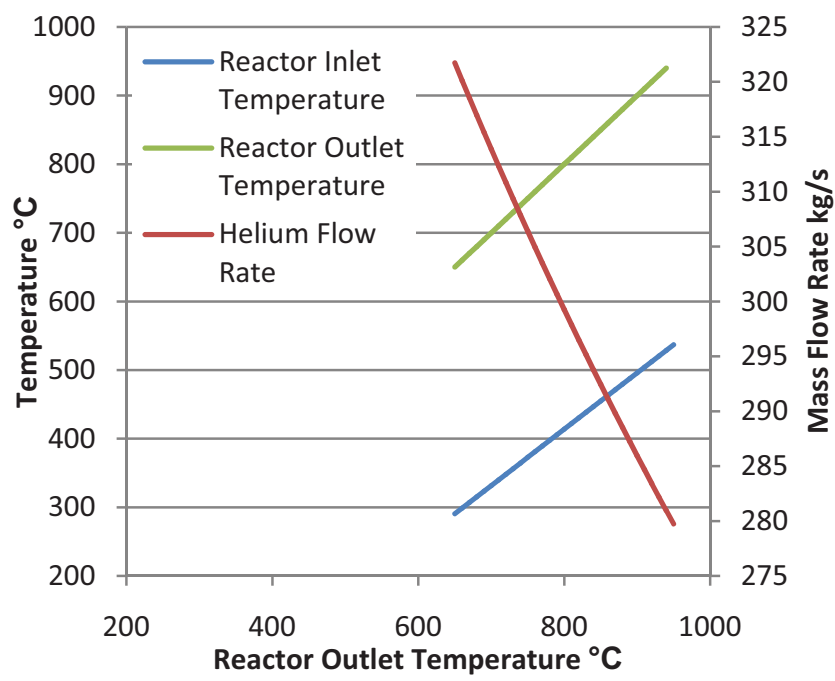

Figure 2. Reactor inlet temperature and helium flow rate as a function of reactor outlet temperature. 
both conditions are met.

A corresponding maximum steam mass flow rate is plotted based on the maximum process return temperature. At ROTs less than $770^{\circ} \mathrm{C}$, the maximum flow rate increases as the ROT increases because the maximum process return temperature increases. At ROTs greater than $770^{\circ} \mathrm{C}$, the maximum steam flow rate becomes constant because the process return temperature is set at the saturated liquid condition at a pressure of $17 \mathrm{MPa}$ and the inlet temperature is set at $540^{\circ} \mathrm{C}$ resulting in a constant difference across the steam generator on the steam side.

Three parametric lines are plotted based on constant process return temperatures of 100,200 and $300^{\circ} \mathrm{C}$. Since the inlet temperature is constant at $540^{\circ} \mathrm{C}$, the corresponding process steam mass flows are constant regardless of ROT. However the ROT must be greater than $707^{\circ} \mathrm{C}$ at a process return temperature of $300^{\circ} \mathrm{C}$ or the RIT will be adversely affected because the return temperature is too high.

As with the steam case, the helium case was analyzed by varying both the ROT and the process return temperatures, see Figure 18. At the maximum process return temperature conditions, the minimum approach across the intermediate heat exchanger, IHX, is constant for the entire heat exchanger. The maximum process return temperature is affected most by the reactor inlet temperature and therefore follows closely the same trend as the RIT. The circulator power on the secondary helium side however causes the temperature difference between the RIT and the maximum process return temperature to increase slightly as ROT increases.

The maximum process mass flow rate is equal to the primary helium loop due to a fairly constant helium specific heat across large temperature ranges and a constant temperature difference across the IHX.

Constant process return conditions were set at 100, 200, 300 and $400^{\circ} \mathrm{C}$. As the ROT increases at a given process return temperature, the process mass flow decreases. This is due to an increasing temperature difference between the increasing process supply temperature and the constant return temperature. At a given ROT, the mass flow rate increases as the process return temperature increases because the temperature difference decreases.

The maximum process return conditions limit the mass flow rate and process return temperatures. For instance, a process return temperature of $400^{\circ} \mathrm{C}$ can only be achieved at ROTs of $850^{\circ} \mathrm{C}$ or greater without adversely affecting the RIT.

Both the process steam and helium plots show some important concepts that need to be considered when integrating processes with HTGRs. If the reactor inlet

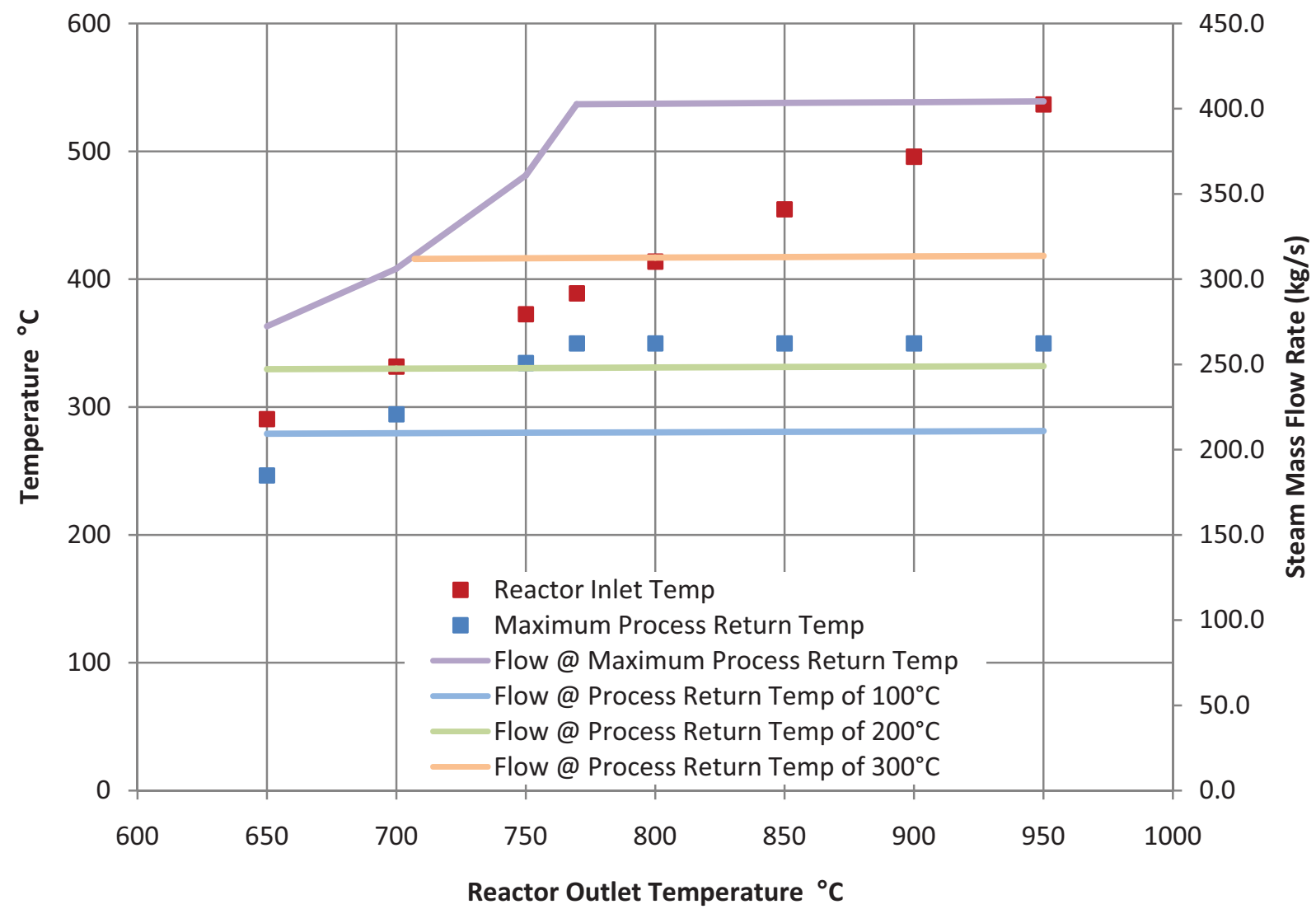

Figure 3. Reactor Process steam results for 600-MWth reactor. 


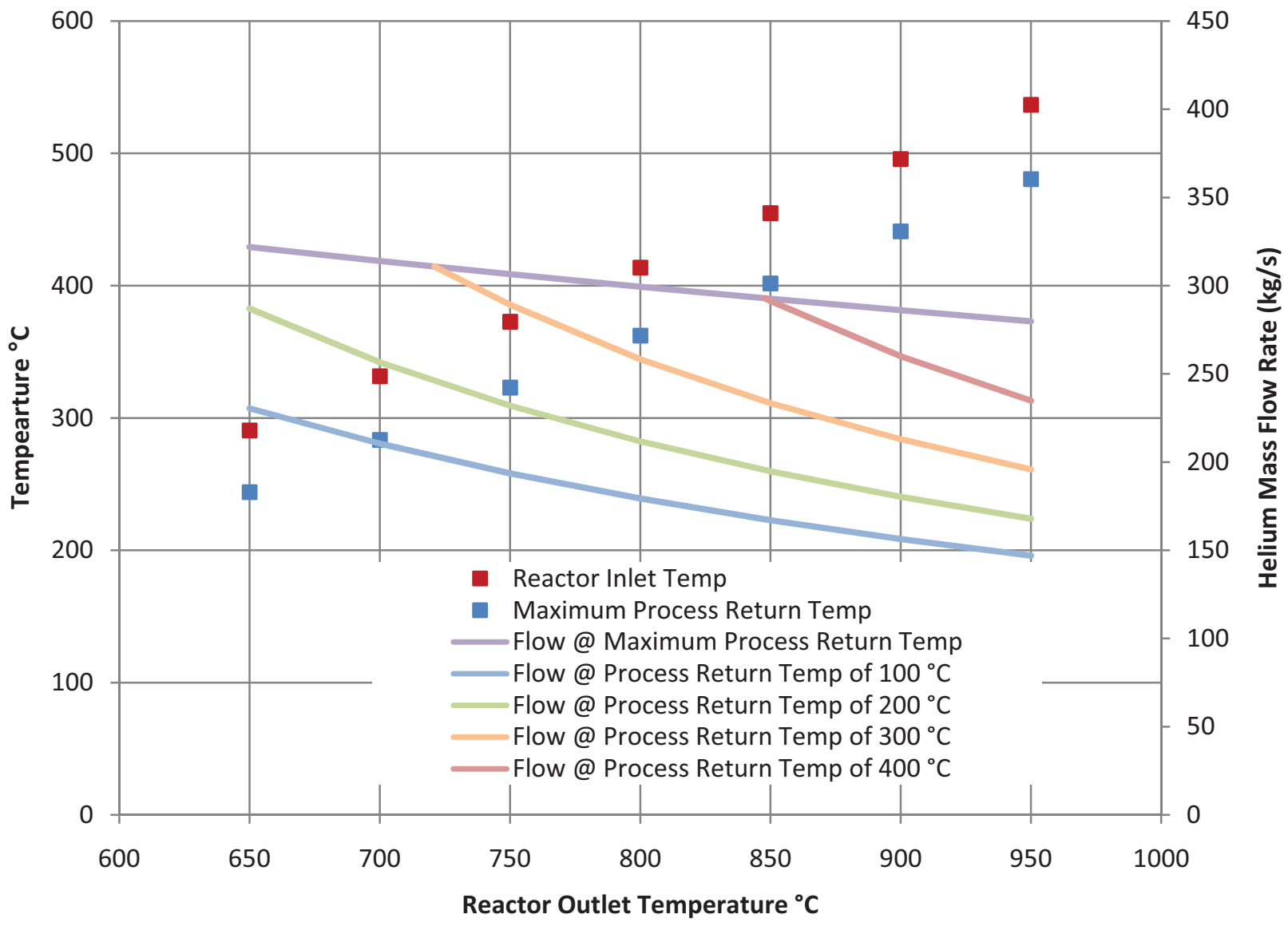

Figure 4. Helium process heat results: Reactor inlet temperature and Maximum process return temperature as a function of ROT; and the secondary loop helium flow rate at various process return temperatures as a function of ROT.

temperature must be maintained, the process return temperature may not exceed the maximum return temperature. The maximum return temperature sets the maximum mass flow rate for the process heat. If the return temperature is greater than the maximum allowable temperature, heat must be rejected or used to bring the return temperature down. If the return temperature is lower than the maximum allowable return temperature, then there is no effect on the reactor inlet temperature, however, the process mass flow rate decreases. The effect this last statement has an important consequence on the integration of heat between the process and the reactor. As an example, if a process needs $900^{\circ} \mathrm{C}$ process heat at a flow rate of $200 \mathrm{~kg} / \mathrm{s}$ or more and the helium return temperature is $400^{\circ} \mathrm{C}$ which is just below the maximum process return temperature of $441^{\circ} \mathrm{C}$, one could use this helium stream in another lower temperature process and drop the return temperature further, for instance to $200^{\circ} \mathrm{C}$. However that would cause the helium flow rate to decrease from $260 \mathrm{~kg} / \mathrm{s}$ to $156 \mathrm{~kg} / \mathrm{s}$ for a single $600 \mathrm{MWt}$ HTGR and would ultimately result in more HTGRs to ensure the correct high temperature process heat at $900^{\circ} \mathrm{C}$.

\section{CONCLUSIONS}

A parametric study was performed to evaluate the heat integration of an HTGR with industrial processes using steam or helium as the heat transfer fluids. Maximum process flow rates are obtained at maximum return temperatures. Higher process return temperatures and flow rates are limited to higher ROTs and are bound at lower ROTs by the maximum conditions. Maximum process flow rates and process return temperatures result in the least number of HTGRs needed for heat integration.

For steam generation at $17 \mathrm{MPa}$, ROTs greater than $770^{\circ} \mathrm{C}$ offer no advantages. Maximum process return temperatures and mass flow rates are set by one of two conditions; below the saturation temperature of the process steam, the process return temperature is strongly affected by the RIT and above the saturation temperature of the process steam, the process return temperature is at the saturated liquid condition. At a given process return temperature, the steam mass flow rate is constant.

If helium is used as the heat transfer fluid, the maximum process flow rate is the same as the primary loop flow rate. At a given process return temperature, the mass flow rate decreases as the ROT increases. At a given ROT, the mass flow rate increases as the process return temperature increases.

\section{ACKNOWLEDGMENTS}

This work was supported by the Idaho National Laboratory, Laboratory Directed Research and Development program and by the U.S. Department of Energy, Office of Nuclear Energy, Next Generation Nuclear Plant Program.

\section{COPYRIGHT STATEMENT}

This manuscript has been authored by Battelle Energy Alliance, LLC under Contract No. DE-AC07-05ID14517 with 
the U.S. Department of Energy. The United States Government retains and the publisher, by accepting the article for publication, acknowledges that the United States Government retains a nonexclusive, paid-up, irrevocable, world-wide license to publish or reproduce the published form of this manuscript, or allow others to do so, for United States Government purposes.

\section{REFERENCES}

1. Thermal Flow and Design of Helium Cooled Reactors, Gilbert Melese, Robert Katz, American Nuclear Society, 1984

2. Preliminary Studies of Coolant By-Pass Flows in a Prismatic Very High Temperature Reactor Using Computional Dynamics, Sato, Johnson, Shultz, INL/CON-09-15885

3. Reactor Pressure Vessel Temperature Analysis of Candidate Very High Temperature Designs, Gougar, Davis, Hayner, Weaver, Oct 2006, INL/CON-0611843

4. Reactor Presssure Vessel Temperature Analysis for Prismatic and Pebble-Bed VHTR Designs, Gougar, Davis, April 2006, INL-EXT-06-11057

5. NGNP Conceptual Design Baseline Document for Conventional Steam Cycle for Process Heat and Cogeneration, Doc Num 51-9103803-001 (internal document) AREVA

6. Engineering Services for the Next Generation Nuclear Plant (NGNP) with Hydrogen Production: Nuclear Heat Supply System Point Design Study for NGNP Conceptual Design, Doc 911167 Rev. 0 (internal document) GA

7. The Next Generation Nuclear Plant INL/EXT-0815118

8. H2-MHR Conceptual Designs Based on the SI Process and HTE Authors Matt Richards, Arkal Shenoy, Ken Schultz, and Lloyd Brown - General Atomics Ed Harvego and Michael McKellar - Idaho National Laboratory Jean-Phillippe-Coupey and S.M. Moshin Reza, Texas A\&M University Futoshi Okamoto - Fuji Electric Systems Norihiko Handa - Toshiba Corporation email: matt.richards@gat.com Third Information Exchange Meeting on Nuclear Production of Hydrogen and Second HTTR Workshop on Hydrogen Production Technologies October 5-7, 2005 Japan Atomic Energy Research Institute, Oarai, Japan

9. Power Cycle and Stress Analyses for High Temperature Gas-Cooled Reactor, C. Oh, R. Barner, C. Davis, B. Hawkes, J. Morton, S. Sherman, May 2007, INL/CON-06-12036

10. The Modular Helium Reactor for Hydrogen Production, INL/CON-06-11320 M. Richards, A. Shenoy, K. Schultz, L. Brown, M. Fukuie, E. Harvego 